\title{
Are leaf functional traits 'invariant' with plant size and what is 'invariance' anyway?
}

\author{
Charles A. Price ${ }^{\star, 1}$, lan J. Wright ${ }^{2}$, David D. Ackerly ${ }^{3}$, Ülo Niinemets ${ }^{4}$, Peter B. Reich ${ }^{5,6}$ and \\ Erik J. Veneklaas ${ }^{1}$ \\ ${ }^{1}$ School of Plant Biology, University of Western Australia, Perth, Western Australia 6009, Australia; ${ }^{2}$ Department of \\ Biological Sciences, Macquarie University, Sydney, New South Wales 2109, Australia; ${ }^{3}$ Department of Integrative \\ Biology, University of California, 3060 Valley Life Sciences Building, Berkeley, California 94720-3140, USA; ${ }^{4}$ Institute of \\ Agricultural and Environmental Sciences, Estonian University of Life Sciences, Kreutzwaldi 1, Tartu 51014, Estonia; \\ ${ }^{5}$ Department of Forest Resources, University of Minnesotam 1530, Cleveland Avenue North, St. Paul, Minnesota \\ 55108; USA; and ${ }^{6}$ Hawkesbury Institute for the Environment, University of Western Sydney, Locked Bag 1797, Penrith, \\ New South Wales 2751, Australia
}

\section{Summary}

1. Studies of size-related plant traits have established a suite of mathematical functions describing whole plant investment and allocation. In parallel, studies of plant 'economic spectra' have measured the scaling and variance composition of traits related to the major dimensions of both structure and function. Here, we explore the intersection of these two broad areas by exploring the notion that many leaf economic traits are invariant with species differences in adult plant size. Invariant traits are those that do not change with plant size and are invoked as a key simplifying assumption of prominent models that purport to explain the scaling of plant size and metabolism. Unfortunately, leaf trait invariance is neither well defined nor understood and has never been critically evaluated.

2. Using a global plant trait data set, we evaluated whether nine key traits can be considered as effectively invariant as a function of the maximum height of plant species, within and across plant growth forms and within and across broad taxonomic groups. We also examine the influence of habitat, biome and global spatial scales on the size-relative variance in plant functional traits.

3. We suggest that while invariance is an intuitive concept, an objective statistical definition is elusive. Expanding on ideas drawn from the study of life-history invariants, we propose five criteria to identify traits that are effectively invariant, depending on the research question.

4. We show that all studied 'leaf economic spectrum' (LES) traits approach invariance within and between herbaceous and woody plant groups, angiosperms and gymnosperms, and within most biome and habitat types. Individual leaf area, however, shows a modest increase with plant size, and there are significant shifts in the average LES trait values at a given plant maximum height, among the plant growth forms and taxonomic groups.

5. Our results demonstrate that generally, LES traits show little interspecific variation with maximum plant height, which provides some support for attempts to model plants with 'average' leaf properties. Our work also highlights the need for a better understanding of the drivers of leaf size variation within and across individuals, functional groups, clades, biomes and habitats.

Key-words: leaf area, leaf economic spectrum, metabolic scaling theory, metabolic theory of ecology, plant functional traits, plant height

\section{Introduction}

Biologists have long recognized body size as one of life's principal dimensions (Galilei 1638; Rubner 1883; Kleiber

*Correspondence author. E-mail: charles.price@uwa.edu.au
1932; Brody 1945). The publication of several compendia of allometric relationships for animals (Peters 1983; Calder 1984; Schmidt-Nielsen 1984; Charnov 1993) and plants (Niklas 1994) and the development of an array of synthetic theoretical approaches (Kooijman 1993; West, Brown \& Enquist 1997; Brown et al. 2004) have further established 
body size as one of the principal drivers underlying variability in organismal metabolic requirements, biomechanical demands and life-history strategies, both within and across clades. This has led to increased efforts aimed at understanding the mechanistic drivers of the allometry of metabolism and mass, and the suite of biological phenomena that are tied to this central pattern.

One prominent recent approach, known as the Metabolic Theory of Ecology (MTE, Brown et al. 2004), proposes a mechanism for the origin of quarter power scaling of metabolism with mass and numerous related scaling phenomena. MTE has generated strong interest and controversy (e.g. Dodds, Rothman \& Weitz 2001; Kozlowski \& Konarzewski 2004; Glazier 2006) and has been linked to numerous patterns across plants including (but not limited to) metabolic allometry (Reich et al. 2006; Enquist et al. 2007; Mori et al. 2010), ontogenetic growth (West, Brown \& Enquist 2001), biomass partitioning (Enquist \& Niklas 2002; Price, Enquist \& Savage 2007), morphological allometry (Price, Enquist \& Savage 2007) and forest structure (Enquist, West \& Brown 2009; West, Enquist \& Brown 2009). For more information on MTE, we direct readers to recent reviews (Coomes 2006; Muller-Landau et al. 2006a,b; Savage, Deeds \& Fontana 2008; Price et al. 2010, 2012; Sibly, Brown \& Kodric-Brown 2012).

Biologists have also long held an interest in the nature of functional trait variability within and across organisms. Functional traits have been defined as 'morpho-physiophenological traits which impact fitness indirectly via their effects on growth, reproduction and survival' (Violle et al. 2007). For plant leaves, the analyses of both continental (Reich et al. 1999) and global scale data sets (Wright et al. 2004) have identified a series of trade-off curves known as the global leaf economic spectrum (LES) (Wright et al. 2004). The spectrum represents a set of leaf physiological traits and trade-offs that are strongly indicative of species growth patterns and life-history strategies. A series of key papers has shown that this suite of traits covaries strongly across plants and represents, coarsely, a slow-growth to fast-growth continuum (Reich et al. 1999; Diaz et al. 2004; Wright et al. 2004; Reich 2014). Multi-dimensional analyses of global data compilations of six of these traits have shown that a striking $74 \%$ of the variability across a set of core traits is explained by the first principal axis (Wright et al. 2004). Plants at the slow end of the continuum typically have high leaf mass per area (LMA), long leaf life span, low mass-based photosynthetic capacity and dark respiration and low nitrogen and phosphorus concentrations per unit mass, when compared to the fast end of the continuum (Reich, Walters \& Ellsworth 1997; Wright et al. 2004). Nevertheless, within this broad spectrum, plants with similar ecological strategies tend to cluster in groups defined by: growth habit, life-form, leaf habit and tolerance to drought and shading (Reich, Walters \& Ellsworth 1997; Hallik, Niinemets \& Wright 2009).

The analyses of several large regional or global data sets have demonstrated that the principal components associated with some leaf traits, such as leaf area, thickness or leaf mass per area (Diaz et al. 2004), or leaf mass per area and leaf mean area (Wright et al. 2007), are orthogonal to the principal component associated with plant canopy height. Similarly, leaf economic traits and wood economic traits have also been shown to be orthogonal in some systems (Baraloto et al. 2010) but not necessarily in general (Reich 2014).

Here, we explore the intersection of MTE and LES. On the one hand, the influence of body size as a driver of morphological and physiological variability is well-established. On the other hand, a growing body of work has established that plant size and suites of physiological or 'economic' traits are often orthogonal to one another. We propose that plant body size and LES traits can be linked by evaluating the variance in plant functional traits and plant body size, relative to one another. It has been suggested that some leaf traits and plant size represent independent axes of ecological and evolutionary diversity (Ackerly 2004). But to what leaf functional traits does this apply, at what spatial scale, and are those traits invariant with plant size? The use of the term invariance here (which we discuss in detail below) means that the trait in question shows little variability and that variability does not change systematically with plant size. Invariant traits are orthogonal, but orthogonal traits may, or may not be, invariant. Further, with natural selection acting locally and differentially across habitats, how is it that a global pattern of invariance might emerge?

These two areas have been linked previously via a central assumption of the MTE plant model [a.k.a. WBE (West, Brown and Enquist) model] that the size and functional traits of leaves are invariant with plant size (West, Brown \& Enquist 1999). The specific assumption described in the original model presentation is that '. . . the number of tubes in a petiole which is taken to be an invariant.', that is, the number and size of conduits in a leaf petiole is invariant with plant size (West, Brown \& Enquist 1999) or that both conduits and leaf size are invariant (West, Enquist \& Brown 2009). In other words, the terminal units on a plant - leaves, supplied by petiolar vasculature - were assumed to vary little (or at least not systematically) with plant size. An implicit assumption is that other leaf functional traits are also invariant, for example those related to metabolism such as those described within the leaf economic spectrum. How do we evaluate these simplifying assumptions? Clearly, most biological traits are variable (and leaf traits are known to vary ontogenetically with size), so our question becomes in essence, is the variability uncorrelated with species differences in size, or if it is correlated, is the correlation weak enough that it will have little influence on model predictions?

Here, we expand upon previous work by combining two large data sets, one containing measurements for several measures of plant size including height, stem diameter and canopy spread (www.americanforests.org/our-programs/ bigtree), and a global data set of plant economic traits 
(GLOPNET; Wright et al. 2004) containing measurements for a number of LES traits: leaf mass per area (LMA), photosynthetic capacity per unit mass $\left(A_{\text {mass }}\right)$ or area ( $\left.A_{\text {area }}\right)$, dark respiration rate $\left(R_{\text {mass }}\right)$, leaf life span (LL), nitrogen content per unit mass $\left(N_{\text {mass }}\right)$ or area $\left(N_{\text {area }}\right)$, phosphorus content per unit mass $\left(P_{\text {mass }}\right)$ or area $\left(P_{\text {area }}\right)$. The data set also contains data on individual leaf size (measured as leaf area) and maximum plant height, which are not typically considered LES traits per se.

We discuss the reasons why an objective statistical definition of invariance is challenging, despite its intuitive appeal, and argue that a more productive approach is to quantify and discuss the relative variance in traits of interest. We then utilize the combined data sets to evaluate the variance in eight LES traits and leaf area, all relative to plant height, a proxy for overall plant size. Looking at woody and herbaceous species together and separately, within angiosperms and gymnosperms, and within different biome and habitat types, we find that most leaf functional traits are substantially less variable than, and show little to no systematic variation with, plant size. Importantly, however, individual leaf area itself increases modestly with plant size, both within woody species and across all plants. In addition, we find an increase in the amount of variance in LES traits explained by plant height, at smaller spatial scales. We speculate on some possible drivers of these patterns and discuss the implications of our findings for understanding ecological distributions of leaf traits and on future attempts to model the general properties of plants.

\section{ARE BIOLOGICAL TRAITS INVARIANT?}

Within biology, the idea of invariant quantities can be found in many areas from food web studies (Briand \& Cohen 1984) to species-area relationships (Preston 1960). One area where they have garnered considerable attention is in the study of organism life histories (Charnov 1993). These traits are usually referred to as dimensionless invariants, and examples include the ratio of weaning mass to adult mass or the ratio of the age at maturity to average life span. In all of these studies, variability exists in the biological quantities in question, but the variability is much less than that of body size. In an attempt to add clarity to the issue, Savage et al. (2006) discuss two types of invariance: 'type $\mathrm{A}$ ' invariance, in which a biological characteristic does not vary systematically with another characteristic, such as body size, and (less commonly) 'type B' invariance, in which a biological characteristic exhibits a unimodal central tendency, suggestive of an optimal or constrained value, and varies over a limited range, relative to the variable to which it is being compared. However, while we recognize that the idea of invariant traits is somewhat intuitive, coming up with a rigorous definition for quantifying it is challenging.

Within mathematics or physics, invariance is clearly defined as a system unaffected by a designated operation, such as a transformation of coordinates. While plants typically lack suites of homologous landmarks, such as the location of bone features, that have proven useful in the analysis of coordinate transformations in animal evolutionary studies (Thompson 1917; Bookstein 1991), the transformation of coordinates can be thought of as an increase in body size with regularly collected measures such as plant height, stem diameter or canopy spread serving as general proxies for plant size.

Invariant means 'non-variable' or 'lacking' variance. Clearly, most biological traits, from conduit dimensions to leaf size, exhibit variability. Certainly, the leaf traits we discuss here all vary: within individual plants, among individuals within a species and across plant species. Thus, statements such as the assumption of invariant conduit dimensions in West, Brown \& Enquist (1999) or conduit dimensions and leaf size in West, Enquist \& Brown (2009) must be viewed as simplifying model assumptions (Price et al. 2012). But, how much variability can exist in a given trait for it still to be considered invariant? Unfortunately, the exact meaning of invariance in biology is not well defined, creating confusion regarding its definition and interpretation (Charnov 1993; Nee et al. 2005, 2006; Savage et al. 2006). As biology and ecology are largely concerned with the study of variability, the adoption of the term 'invariant' from mathematics and physics will likely continue to lead to confusion. We recognize the utility of viewing traits as 'invariant' within some modelling approaches; however, we offer that it is more accurate to describe traits as 'approaching invariance' or 'effectively invariant', which recognizes invariance as a theoretical ideal, but preserves the inherent variable nature of biological traits. Moreover, as the concept of an invariant trait is poorly understood, we emphasize the relative nature of this concept: invariance in a biological context is always relative to another trait.

We expand upon earlier work (Charnov 1993; Savage et al. 2006) and propose five criteria that can help in identifying traits that approach invariance:

1. Low variance in the $y$-variable relative to the $x$-variable (Charnov 1993; Savage et al. 2006). As is typical within the field, we treat size as the $\mathrm{x}$-variable and the trait of interest as the $\mathrm{y}$-variable. Coming up with an a priori guideline for exactly how much more variability is expected in the $\mathrm{x}$-variable than the $\mathrm{y}$-variable is challenging. We suggest that, rather than using some arbitrary cut-off value for invariance, investigators simply report the ratio of variances and interpret their findings in the light of this value. This approach is valid only when variables have the same units or if they are examined on logarithmic scales. Note that the ratio of variances also corresponds to the standardized major axis slope of the relationship between the variables, and so approaches zero as variance in the $y$-variable declines relative to size (see Criterion 4).

2. Modal variance in the $y$-variable, which may be suggestive of an optimal value (Charnov 1993; Savage et al. 2006). In practice, it is likely that due to the inherent 
multiplicative nature of growth, most traits of interest will have frequency distributions that are close to normal on linear or logarithmic scales (Kerkhoff \& Enquist 2009). Thus, for many traits, the distribution of variance might be consistent with the expectation of the normal curve, that is, $95 \%$ of the observations will fall within two standard deviations. However, it is also likely that some traits will have frequency distributions that depart from normality, yet still contain much less variability than plant size for example.

3. Low coefficient of determination ( $R^{2}$ value). Regression fits to bivariate plots should show that size has little to no explanatory power with respect to the trait of interest. Note that a low $R^{2}$ merely says that two variables are unrelated and says nothing about the degree of variance of either one. It is useful, however, when applied along with other criteria because it directly addresses whether the central tendency of one trait varies in relation to another.

4. Low slope. Regression fits to bivariate plots should have a shallow slope which may also demonstrate that size has little to no explanatory power with respect to the trait of interest. Low slopes will often be correlated with low variance ratios (Criterion 1 and identical if using SMA regression) and low $R^{2}$ values (Criterion 3 ) (Warton et al. 2006), but provide a further line of evidence for assessing invariance.

5. Isometric variation. This method is commonly used in the study of life-history invariants (Charnov 1993). If two traits show an isometric relationship (i.e. a slope of 1 on a $\log -\log$ plot), then their ratio will be invariant across the spectrum of variation in the two traits and may also be invariant (by criteria above) when regressed against some third variable, typically body size (see Savage et al. 2006 for a discussion on this topic). The choice of SMA vs. OLS regression is critical in assessing isometric relationships, as uncorrelated variables will have a slope of 1 under SMA regression, so in practice, it is important to consider the both slope and the $R^{2}$ to make a substantive claim of isometric variation.

For situations in which invariance is a simplifying model assumption, further insight can be gained from modelbased sensitivity analysis. For example, one can explore how changes in model parameters influence outcomes or predictions. If the model is highly sensitive, then even small amounts of variation (or shallow slopes) could be sufficient to drive change. If a model has low sensitivity, then steeper slopes might have little influence on model predictions.

\section{Materials and methods}

Data for our analyses come from two sources. The first is the 'GLOPNET' data set (GLObal Plant trait NETwork; Wright et al. 2004). A subset of the data base contains maximum height measurements co-occurring with the leaf economic traits we considered, where maximum height corresponds to the maximum observed height within a study location or data set. A total of 540 records in the data base had height and leaf area $\left(\mathrm{cm}^{2}\right)$ or at least one of the following LES trait measurements: leaf mass per area (LMA, $\mathrm{g} \mathrm{m}^{-2}$ ), photosynthetic capacity on a mass ( $A_{\text {mass }}$,

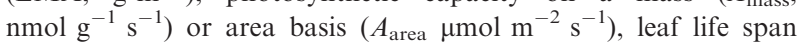
(LL, months), nitrogen content per unit mass $\left(N_{\text {mass }} \%\right)$ or area $\left(N_{\text {area }}, \mathrm{g} \mathrm{m}^{-2}\right)$, phosphorus content per unit mass $\left(P_{\text {mass }} \%\right)$ or area $\left(P_{\text {area }}, \mathrm{g} \mathrm{m}^{-2}\right)$.

Additional maximum tree height data comes from the registry of Big Trees which is maintained by the non-profit group American Forests (www.americanforests.org). Tree species within the registry are considered champions based on the following composite score: circumference at breast height (in), plus tree height (ft), plus one-fourth of the average crown spread (ft), a formula giving a greater weighting to tree height and circumference than spread. One hundred and sixty species in the Big Tree data base were also represented in full GLOPNET data set, and we paired the height measurements from Big Tree data base with the corresponding leaf trait data from GLOPNET. As the GLOPNET data set does not contain bole circumference of crown radius data, these data from the Big Tree data set were not used.

The WBE model, upon which MTE rests, assumes an idealized plant where stems, branches and petioles only fulfil support and hydraulic supply roles, that is, they are considered non-photosynthetic, and thus this typically applies to woody species (West, Brown \& Enquist 1999). Scaling predictions for herbaceous plants or plants with photosynthetic stems may still follow the predicted quarter power scaling relationships, provided their branching geometry meets model assumptions, but (all else being equal) would be expected to have different normalizations (y-intercepts) for various scaling relationships. Therefore, to allow for this potential difference, we examined trait means and correlations for all species together, and within woody and herbaceous growth forms separately. Given the anatomical and physiological differences between angiosperms and gymnosperms, particularly with respect to leaf form and hydraulic architecture, we also examined differences between these two major clades of seed plants.

Natural selection is a local-scale process, thus plants growing within a biome or habitat are typically subject to more similar selective pressures than plants across biomes or habitats. If LES traits are invariant with plant height globally, this can arise in one of two ways: (i) LES traits are invariant with height at both local and global scales, (ii) LES traits vary systematically with height within some or all habitats and/or biomes, yet shifts in the elevation of these traits between habitat or biomes and an increase in the total range of height sampled decrease the explanatory power of height across these local-scale groupings. To evaluate which of these two possibilities is operating within our data set, we also grouped species according to the habitat and biome within the GLOPNET data set. Biome classifications follow (Whittaker 1975; Wright et al. 2004) and include the following types: boreal, alpine, woodland, temperate forest, tropical forest and rain forest. We determined habitat classifications from the original published papers leading to 21 distinct habitat classifications (Table S1). One of these, 'high elevation grasslands', had only five observations and was not included in statistical analysis at the habitat level. Data from two papers were from a mosaic of habitats across a range of sites and were also not included in the habitat analysis (Table S1). The Big Tree data set does not contain habitat or biome classifications, thus was not included in the analysis of biome or habitat level patterns.

All bivariate relationships were log-transformed (base 10), to meet the assumption of homogeneity of variance, and fit with an ordinary least-squares (OLS) regression slopes, with height as the predictor variable. In line with Criterion 1, we examined the relative variance in plant height relative to the variance in the LES traits and leaf area. To evaluate Criterion 2, we explored the shape 
and dispersion of each LES trait and leaf area. In line with Criteria 3 and 4, we used three common metrics to inform our consideration of whether traits were effectively invariant: (i) the slope, (ii) the coefficient of determination $\left(R^{2}\right)$, which estimates the strength of the linear relationship between variables, and (iii) the $P$-value, which tests for an association between $X$ and $Y$ and indicates whether the relationship under consideration has a slope that is different than zero. We further tested for a common slope between woody and herbaceous groups. If a common slope was found, a further test was performed to determine whether there had been a shift in elevation between groups (Warton et al. 2006).

Performing numerous regressions potentially increases the family-wise error rate or the chance of a type 1 error. To correct for the large number of regressions, we used the Holm-Bonferroni (Holm 1979) method to adjust $P$-values within each 'family', where our family groupings were (i) across angiosperms, gymnosperms, herbaceous and woody taxa (Table 1); (ii) at the biome level (Table 2); and (iii) at the habitat level (Table S2). As reliance on corrected $P$-values alone would bias our analysis towards a finding of invariant relationships, when considered in terms of significance of regressions, we report uncorrected $P$-values in Tables 1 and 2 and Table $\mathrm{S} 2$ and note those $P$-values that remain significant following the Holm-Bonferroni correction.

\section{Results}

There were 648 woody plant species (trees or shrubs) and 52 herbaceous species in the combined data set. The grasses were represented by only 15 observations and were grouped with the herbaceous plants for analyses. The total number of combined height-trait measurements for each relationship is given in the fourth column of Tables 1 and 2 and Table S2. Sample sizes range from a minimum of 19 to a maximum of 679 for the growth form groupings (Table 1); a minimum of 14 to a maximum of 624 for the taxonomic grouping (angiosperm or gymnosperm); a minimum of 8 to a maximum of 207 for the biome grouping (Table 2); and a minimum of 8 to a maximum of 121 for the habitat grouping (Table S2). Some trait combinations contained insufficient data and are thus not reported. A full list of species and their corresponding measurements are included in the Supporting Information, Table S1.

In our data set, plant height varied from a minimum of $0.02 \mathrm{~m}$ in Oxytropis nigrescens to a maximum of $62.8 \mathrm{~m}$ for Picea sitchensis or over 3.5 orders of magnitude on a $\log$ scale. The overwhelming majority of extant land plant species fall within this range.

Before reporting coefficients of determination $\left(R^{2}\right)$, we first look at relative variance in each relationship. As seen in Table 3, the variance in (log-transformed) plant height was always greater than the variance in (log-transformed) leaf economic traits, ranging from 2.9 to 11.4 times greater across all plants. These results are generally consistent with Criterion 1, the suggested convention that the variance in the $\mathrm{y}$-variable should be less than the variance in the $\mathrm{x}$-variable for a trait to be considered invariant (Savage et al. 2006), with an order of magnitude more variance (11.4) representing a stronger case for invariance. Similarly, consistent with Criterion 2, all traits we examined are unimodal, and as seen in Fig. 1 and in Table 3, 95\% of the observations for 7 out of 9 functional traits fell within two standard deviations of the mean, and for the remaining two traits, $93 \%$ of the observations were within two standard deviations.

In contrast to the other leaf traits, the variance for leaf area is greater than that of plant height. This is likely related to the fact that leaf area is proportional to length squared while plant height is proportional to length to the first power. If we consider the log of the square root of leaf area, the variance is then less than that for plant height and similar to the other traits we have examined (Table 3). This would also likely be true if we considered leaves and trunks on the same scale, that is, volume or mass.

In agreement with Criterion 3, the coefficient of determination $\left(R^{2}\right)$ was consistently very low across the relationships we examined, with a mean value of 0.04 (Table 1). Considering both within and among growth forms and taxonomic groupings (Figs 2 and 3, Table 1), only 12 out of 43 of the bivariate relationships had OLS slopes that were statistically different from zero $(P<0 \cdot 05)$, largely satisfying Criterion 4 (and following a Holm-Bonferroni correction, this number dropped to just 8 out of 43 ; $P<0.05)$. However, even for those 12 relationships, the average $R^{2}$ value was only $0 \cdot 105$, and thus plant height has only modest explanatory power for this suite of leaf functional traits. The relationship with the highest $R^{2}$ value was that of leaf area which increased with plant height with a slope of 0.573 for all plants $\left(R^{2}=0.15\right)$ and a slope of 0.765 for woody plants $\left(R^{2}=0.25\right.$; Table 1$)$.

Just as for the all-species analyses, in general, the biome-specific relationships showed notably low $R^{2}$ values, averaging $0 \cdot 11$ (Fig. 4, Fig. S2, Table 2). Fifteen out of 42 relationships $(36 \%)$ were statistically significant (dropping to 8 with a Holm-Bonferroni correction), and among this 15 , the average $R^{2}$ value was $0 \cdot 2$ (Table 2). The mean $R^{2}$ across habitat groupings was slightly higher at 0.17 (Table S2). Twenty-eight out of $109(26 \%)$ relationships at the habitat scale were different than zero, and the mean $R^{2}$ for significant $(\alpha=0.05)$ non-zero relationships was $0 \cdot 38$. Following the Holm-Bonferroni correction at the habitat level, only 5 of 109 relationships differed from zero (Table S1). In summary, adult plant height has relatively little explanatory value with respect to interspecific differences in LES traits in most biome or habitat types.

For woody and herbaceous groups, six of the traits that we have examined contained sufficient data to allow a test for a common slope between groups (LMA, $N_{\text {mass }}, N_{\text {area }}$, $A_{\text {mass }}, A_{\text {area }}$ and leaf size; Table 1). Of these, four traits shared a common slope across woody and herbaceous groups: $N_{\text {mass }}, N_{\text {area }}, A_{\text {mass }}$ and $A_{\text {area }}(P$-value $>0.05$, Table 1). Among these, there was a significant difference in slope elevation between woody and herbaceous species for $N_{\text {area }}$ and $A_{\text {area }}$ relationships ( $P$-value $\left.>0.05\right)$. Similarly, nine of the traits allowed us to test whether the slopes were common between angiosperms and gymnosperm groups. Six of those tests showed no differences in slopes $(P$-value $>0.05)$. Of those six, five had significant shifts in elevation between groups ( $P$-value $>0.05)$. 


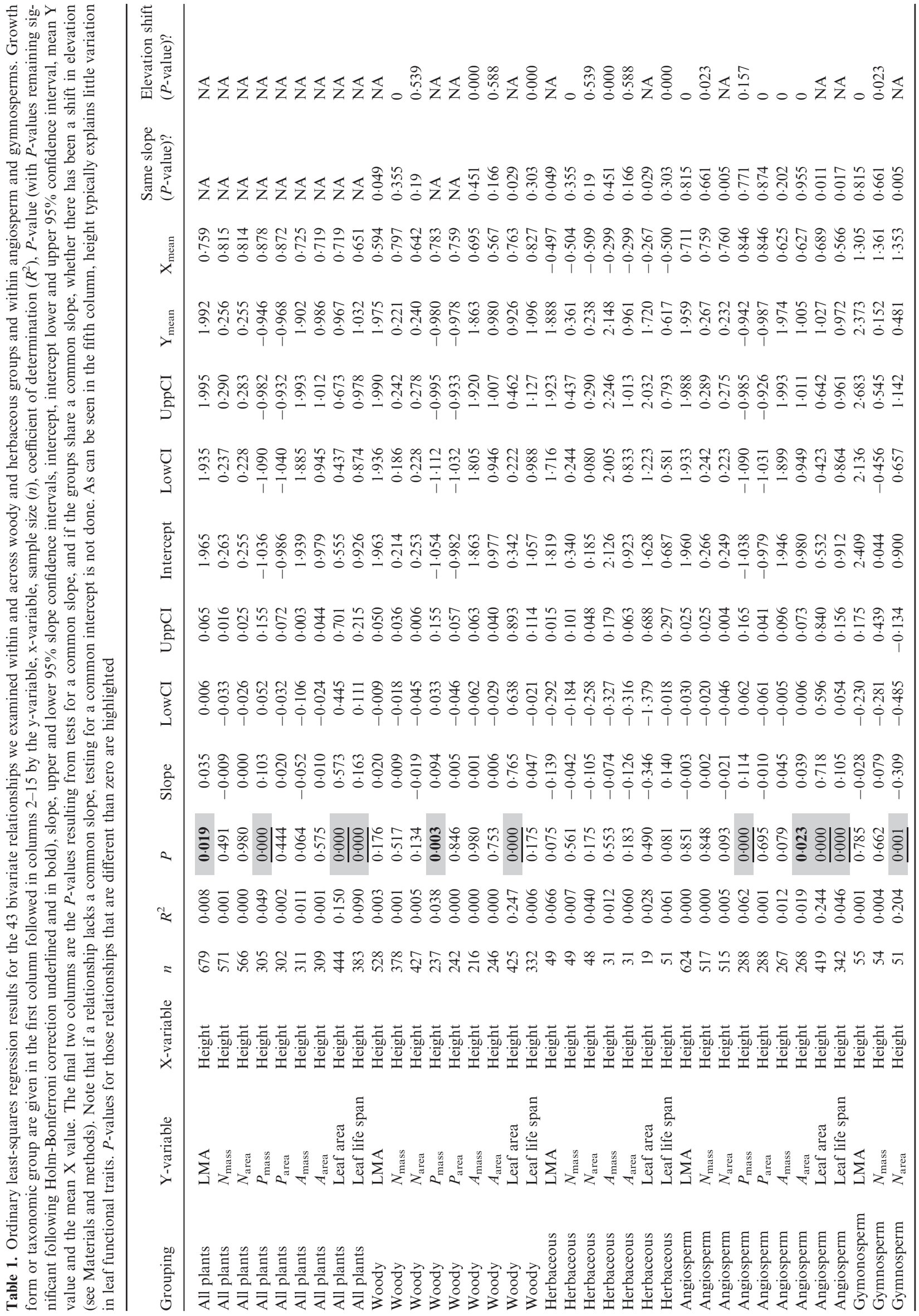




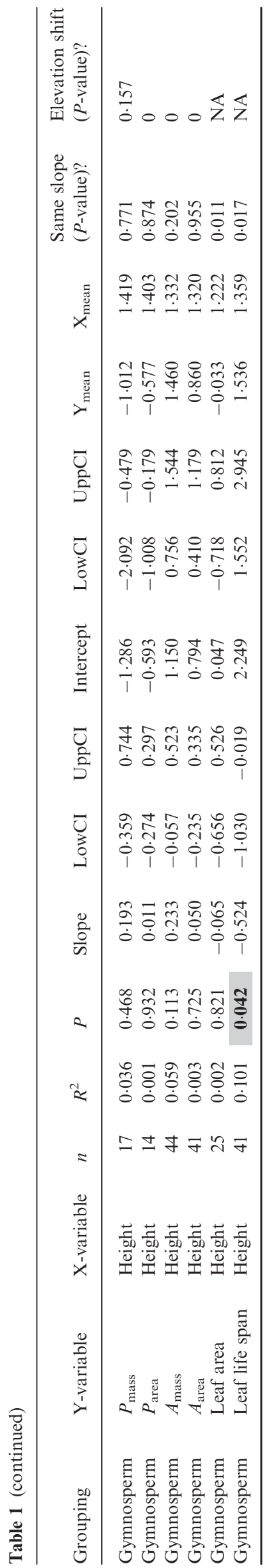

The amount of variance explained within and across each relationship increased going from global to biome to habitat scale (Fig. 4). The mean $R^{2}$ values were $0 \cdot 01,0 \cdot 11$ and 0.16 at global, biome and habitat scales, respectively.

\section{Discussion}

How constant is constant enough to be considered invariant is worthy of much thought, considering that noisy field parameters are our stock in trade and will be forever.Charnov (1993), Life History Invariants.

Collectively, our results suggest that interspecific LES traits vary little, if at all, as a function of plant height. As seen in Figs 2 and 3, Figs S1 and S2 (Supporting information), and in Tables 1 and 2, and Table S2, the LES traits we evaluated show little or no systematic variation with plant height based on growth form, taxonomic group, biome or habitat. This reinforces previous work by expanding the suite of traits analysed and suggests that height and leaf functional trait variability are indeed largely orthogonal to one another (Diaz et al. 2004; Wright et al. 2007; Laliberté et al. 2012). Height and LES traits may represent independent axes upon which natural selection acts within some communities (Ackerly 2004). However, our analysis also shows that there may be modest trends in some LES traits with plant height within some biomes or habitats (Table 2, Table S2, Fig. 3, Fig. S2).

This suggests that while some communities exhibit separation in LES traits based on height (Thomas 1996; Falster \& Westoby 2005; Niinemets 2010), when looking across multiple communities, shifts in the location of data (elevation and horizontal position) effectively reduces the explanatory power of height. For example, LMA increases systematically with height in 6 of the 14 habitats we examined (Fig. 3, Table S2). However, there are shifts in the mean LMA values between habitats, and an increase in the total height range such that when looking across angiosperms or gymnosperms, or across plants generally, height has little explanatory power with respect to LMA. This phenomenon is repeated in several of the relationships we examined and is exemplified in Fig. 4, where we see a decrease in the amount of variance explained by height for each functional trait and across all traits when going from habitat to global scales. There is thus a greater likelihood of observing size-based selection on leaf functional traits within local communities. Due to the low sample sizes within some of these biomes and habitats (Table 2 and Table S2), we caution against over-interpretation of these patterns. Subsequent analyses of these trends in larger, more comprehensive data sets would prove enlightening.

Looking at the variance structure also suggests that the LES traits we examined display consistently low variance, with shallow slopes and low $R^{2}$ values, when compared with plant height. The $\log _{10}$ variance in plant height is greater than $\log _{10}$ leaf trait variance in all cases but that of 
Table 2. Ordinary least-squares regression results for the 42 bivariate relationships we examined when grouping species by biome. Biome classifications are given in the first column followed in columns $2-14$ by the y-variable, $\mathrm{x}$-variable, sample size $(n)$, coefficient of determination $\left(R^{2}\right), P$-value (with $P$-values remaining significant following Holm-Bonferroni correction underlined and in bold), slope, upper and lower $95 \%$ slope confidence intervals, intercept, intercept lower and upper 95\% confidence interval, mean $\mathrm{Y}$ value and the mean $\mathrm{X}$ value. $P$-values for those relationships that were different than zero are shown in bold

\begin{tabular}{|c|c|c|c|c|c|c|c|c|c|c|c|c|c|}
\hline Biome & $\begin{array}{l}\text { Y- } \\
\text { variable }\end{array}$ & $\begin{array}{l}\mathrm{X}- \\
\text { variable }\end{array}$ & $n$ & $R^{2}$ & $P$ & Slope & LowCI & UppCI & Intercept & LowCI & UppCI & $Y_{\text {mean }}$ & $\mathrm{X}_{\text {mean }}$ \\
\hline $\begin{array}{l}\text { Temperate } \\
\text { forest }\end{array}$ & LMA & Height & 207 & $0 \cdot 162$ & $\underline{0}$ & $0 \cdot 158$ & $0 \cdot 109$ & $0 \cdot 207$ & 1.835 & 1.794 & 1.877 & 1.926 & 0.576 \\
\hline $\begin{array}{l}\text { Temperate } \\
\text { forest }\end{array}$ & $N_{\text {mass }}$ & Height & 118 & $0 \cdot 107$ & $\underline{0}$ & -0.096 & $-0 \cdot 147$ & $-0 \cdot 045$ & $0 \cdot 272$ & $0 \cdot 220$ & $0 \cdot 324$ & $0 \cdot 201$ & 0.738 \\
\hline $\begin{array}{l}\text { Temperate } \\
\text { forest }\end{array}$ & $N_{\text {area }}$ & Height & 118 & 0.048 & 0.017 & $0 \cdot 052$ & $0 \cdot 010$ & $0 \cdot 094$ & $0 \cdot 181$ & $0 \cdot 138$ & $0 \cdot 224$ & $0 \cdot 219$ & 0.738 \\
\hline $\begin{array}{l}\text { Temperate } \\
\text { forest }\end{array}$ & $P_{\text {mass }}$ & Height & 19 & $0 \cdot 005$ & 0.768 & $0 \cdot 025$ & $-0 \cdot 151$ & $0 \cdot 201$ & $-1 \cdot 343$ & $-1 \cdot 462$ & $-1 \cdot 224$ & $-1 \cdot 328$ & $0 \cdot 581$ \\
\hline $\begin{array}{l}\text { Temperate } \\
\text { forest }\end{array}$ & $P_{\text {area }}$ & Height & 19 & $0 \cdot 195$ & 0.058 & $0 \cdot 213$ & -0.008 & $0 \cdot 434$ & -1.393 & -1.543 & $-1 \cdot 243$ & $-1 \cdot 269$ & $0 \cdot 581$ \\
\hline $\begin{array}{l}\text { Temperate } \\
\text { forest }\end{array}$ & $A_{\text {mass }}$ & Height & 117 & 0.065 & 0.005 & $-0 \cdot 112$ & $-0 \cdot 189$ & -0.034 & $2 \cdot 000$ & 1.921 & $2 \cdot 079$ & 1.917 & 0.744 \\
\hline $\begin{array}{l}\text { Temperate } \\
\text { forest }\end{array}$ & $A_{\text {area }}$ & Height & 117 & $0 \cdot 021$ & $0 \cdot 115$ & $0 \cdot 038$ & $-0 \cdot 010$ & $0 \cdot 086$ & 0.901 & $0 \cdot 852$ & 0.949 & 0.929 & 0.744 \\
\hline $\begin{array}{l}\text { Temperate } \\
\text { forest }\end{array}$ & $\begin{array}{l}\text { Leaf life } \\
\text { span }\end{array}$ & Height & 126 & $0 \cdot 13$ & $\underline{0}$ & $0 \cdot 210$ & $0 \cdot 113$ & $0 \cdot 306$ & $0 \cdot 871$ & $0 \cdot 772$ & 0.970 & 1.032 & 0.770 \\
\hline $\begin{array}{l}\text { Temperate } \\
\text { forest }\end{array}$ & Leaf area & Height & 205 & 0.018 & 0.054 & $0 \cdot 152$ & -0.003 & $0 \cdot 307$ & 0.920 & 0.787 & 1.053 & 1.011 & $0 \cdot 598$ \\
\hline Tropical forest & LMA & Height & 19 & 0.007 & 0.727 & -0.053 & $-0 \cdot 366$ & $0 \cdot 261$ & 1.853 & 1.500 & $2 \cdot 205$ & 1.795 & $1 \cdot 101$ \\
\hline Tropical forest & $N_{\text {mass }}$ & Height & 19 & 0.424 & 0.003 & $-0 \cdot 372$ & -0.594 & $-0 \cdot 150$ & 0.761 & $0 \cdot 511$ & $1 \cdot 011$ & $0 \cdot 351$ & $1 \cdot 101$ \\
\hline Tropical forest & $N_{\text {area }}$ & Height & 19 & $0 \cdot 263$ & 0.025 & $-0 \cdot 350$ & $-0 \cdot 649$ & $-0 \cdot 050$ & $0 \cdot 525$ & $0 \cdot 189$ & $0 \cdot 862$ & $0 \cdot 140$ & $1 \cdot 101$ \\
\hline Tropical forest & $P_{\text {mass }}$ & Height & 10 & 0.025 & 0.661 & $-0 \cdot 067$ & $-0 \cdot 405$ & $0 \cdot 271$ & -0.722 & -1.058 & $-0 \cdot 386$ & -0.787 & 0.977 \\
\hline Tropical forest & $P_{\text {area }}$ & Height & 10 & 0.466 & 0.03 & -0.425 & -0.795 & -0.054 & -0.648 & -1.017 & $-0 \cdot 280$ & $-1 \cdot 063$ & 0.977 \\
\hline Tropical forest & $\begin{array}{l}\text { Leaf life } \\
\text { span }\end{array}$ & Height & 19 & 0 & 0.944 & 0.013 & $-0 \cdot 372$ & $0 \cdot 398$ & 1.032 & 0.599 & 1.464 & 1.046 & $1 \cdot 101$ \\
\hline Tropical forest & Leaf area & Height & 9 & $0 \cdot 041$ & 0.602 & $0 \cdot 225$ & -0.750 & $1 \cdot 200$ & $1 \cdot 349$ & $0 \cdot 127$ & $2 \cdot 571$ & 1.628 & $1 \cdot 239$ \\
\hline $\begin{array}{l}\text { Tropical rain } \\
\text { forest }\end{array}$ & LMA & Height & 95 & $0 \cdot 275$ & $\underline{0}$ & $0 \cdot 239$ & $0 \cdot 159$ & $0 \cdot 319$ & 1.621 & 1.528 & 1.715 & 1.887 & $1 \cdot 115$ \\
\hline $\begin{array}{l}\text { Tropical rain } \\
\text { forest }\end{array}$ & $N_{\text {mass }}$ & Height & 91 & 0.025 & $0 \cdot 138$ & -0.058 & $-0 \cdot 135$ & $0 \cdot 019$ & $0 \cdot 289$ & $0 \cdot 199$ & $0 \cdot 379$ & $0 \cdot 224$ & $1 \cdot 111$ \\
\hline $\begin{array}{l}\text { Tropical rain } \\
\text { forest }\end{array}$ & $N_{\text {area }}$ & Height & 90 & $0 \cdot 17$ & $\underline{0}$ & $0 \cdot 173$ & $0 \cdot 092$ & $0 \cdot 253$ & -0.086 & $-0 \cdot 180$ & 0.009 & $0 \cdot 106$ & $1 \cdot 108$ \\
\hline $\begin{array}{l}\text { Tropical rain } \\
\text { forest }\end{array}$ & $P_{\text {mass }}$ & Height & 69 & 0.007 & 0.489 & $-0 \cdot 041$ & $-0 \cdot 160$ & 0.077 & -0.863 & -1.009 & -0.716 & -0.912 & $1 \cdot 195$ \\
\hline $\begin{array}{l}\text { Tropical rain } \\
\text { forest }\end{array}$ & $P_{\text {area }}$ & Height & 69 & $0 \cdot 249$ & $\underline{0}$ & $0 \cdot 266$ & $0 \cdot 153$ & $0 \cdot 379$ & -1.355 & -1.494 & $-1 \cdot 216$ & $-1 \cdot 037$ & $1 \cdot 195$ \\
\hline $\begin{array}{l}\text { Tropical rain } \\
\text { forest }\end{array}$ & $A_{\text {mass }}$ & Height & 27 & 0.08 & $0 \cdot 153$ & $-0 \cdot 187$ & -0.447 & 0.074 & $2 \cdot 191$ & 1.926 & $2 \cdot 456$ & $2 \cdot 019$ & 0.921 \\
\hline $\begin{array}{l}\text { Tropical rain } \\
\text { forest }\end{array}$ & $A_{\text {area }}$ & Height & 26 & 0.04 & 0.327 & $0 \cdot 108$ & $-0 \cdot 115$ & $0 \cdot 330$ & $0 \cdot 856$ & 0.635 & 1.078 & 0.954 & 0.903 \\
\hline $\begin{array}{l}\text { Tropical rain } \\
\text { forest }\end{array}$ & $\begin{array}{l}\text { Leaf life } \\
\text { span }\end{array}$ & Height & 27 & 0.032 & 0.375 & $0 \cdot 184$ & $-0 \cdot 236$ & $0 \cdot 604$ & $0 \cdot 862$ & 0.435 & 1.289 & 1.032 & 0.921 \\
\hline $\begin{array}{l}\text { Tropical rain } \\
\text { forest }\end{array}$ & Leaf area & Height & 83 & $0 \cdot 152$ & $\underline{0}$ & -0.479 & -0.729 & .228 & $2 \cdot 277$ & 1.979 & $2 \cdot 575$ & 1.732 & 1.139 \\
\hline Boreal & $\mathrm{MA}$ & eicht & 51 & 1 & & 6 & 0.073 & 36 & & 2 & 4 & $2 \cdot 040$ & -0.531 \\
\hline Boreal & $N_{\text {mass }}$ & Height & 51 & 0.004 & 0.657 & $-0 \cdot 016$ & -0.087 & $0 \cdot 056$ & $0 \cdot 267$ & $0 \cdot 205$ & $0 \cdot 329$ & $0 \cdot 275$ & $-0 \cdot 507$ \\
\hline Boreal & $N_{\text {area }}$ & Height & 50 & 0.001 & 0.795 & $0 \cdot 011$ & -0.072 & 0.094 & $0 \cdot 301$ & $0 \cdot 228$ & $0 \cdot 374$ & $0 \cdot 295$ & -0.511 \\
\hline Boreal & $P_{\text {mass }}$ & Height & 8 & 0.433 & 0.076 & $0 \cdot 212$ & -0.030 & 0.455 & $-0 \cdot 684$ & -0.879 & -0.488 & $-0 \cdot 840$ & -0.734 \\
\hline Boreal & $P_{\text {area }}$ & Height & 8 & 0.433 & 0.076 & $0 \cdot 261$ & -0.037 & $0 \cdot 560$ & -0.483 & -0.724 & $-0 \cdot 242$ & -0.675 & -0.734 \\
\hline Boreal & $A_{\text {mass }}$ & Height & 19 & 0.065 & 0.293 & $0 \cdot 152$ & $-0 \cdot 144$ & $0 \cdot 448$ & $2 \cdot 084$ & 1.865 & $2 \cdot 302$ & 1.990 & $-0 \cdot 615$ \\
\hline Boreal & $A_{\text {area }}$ & Height & 19 & 0.031 & 0.473 & $0 \cdot 050$ & -0.094 & $0 \cdot 194$ & 1.060 & 0.954 & $1 \cdot 166$ & 1.029 & $-0 \cdot 615$ \\
\hline Boreal & $\begin{array}{l}\text { Leaf life } \\
\text { span }\end{array}$ & Height & 53 & 0.02 & $0 \cdot 307$ & $0 \cdot 087$ & -0.082 & $0 \cdot 255$ & $0 \cdot 804$ & $0 \cdot 655$ & 0.953 & 0.758 & -0.530 \\
\hline Woodland & LMA & Height & 151 & 0.003 & 0.534 & -0.024 & -0.099 & 0.052 & $2 \cdot 108$ & $2 \cdot 046$ & $2 \cdot 169$ & $2 \cdot 093$ & 0.622 \\
\hline Woodland & $N_{\text {mass }}$ & Height & 145 & 0.023 & 0.066 & $0 \cdot 051$ & -0.004 & $0 \cdot 105$ & $0 \cdot 215$ & $0 \cdot 171$ & $0 \cdot 260$ & $0 \cdot 247$ & 0.629 \\
\hline Woodland & $N_{\text {area }}$ & Height & 145 & 0.004 & 0.431 & 0.023 & -0.035 & $0 \cdot 081$ & $0 \cdot 315$ & $0 \cdot 267$ & $0 \cdot 362$ & $0 \cdot 329$ & 0.629 \\
\hline Woodland & $P_{\text {mass }}$ & Height & 136 & 0.032 & 0.036 & $0 \cdot 100$ & 0.006 & $0 \cdot 194$ & -1.048 & $-1 \cdot 125$ & -0.970 & -0.984 & 0.635 \\
\hline Woodland & $P_{\text {area }}$ & Height & 136 & 0.043 & 0.016 & 0.093 & $0 \cdot 018$ & $0 \cdot 168$ & -0.979 & -1.041 & -0.916 & -0.920 & 0.635 \\
\hline
\end{tabular}


Table 2 (continued)

\begin{tabular}{|c|c|c|c|c|c|c|c|c|c|c|c|c|c|}
\hline Biome & $\begin{array}{l}\mathrm{Y}- \\
\text { variable }\end{array}$ & $\begin{array}{l}\mathrm{X} \text { - } \\
\text { variable }\end{array}$ & $n$ & $R^{2}$ & $P$ & Slope & LowCI & UppCI & Intercept & LowCI & UppCI & $Y_{\text {mean }}$ & $\mathrm{X}_{\text {mean }}$ \\
\hline Woodland & $A_{\text {mass }}$ & Height & 84 & $0 \cdot 023$ & $0 \cdot 17$ & $-0 \cdot 111$ & -0.269 & $0 \cdot 048$ & $1 \cdot 868$ & 1.772 & 1.964 & $1 \cdot 814$ & 0.485 \\
\hline Woodland & $A_{\text {area }}$ & Height & 84 & $0 \cdot 015$ & $0 \cdot 264$ & $0 \cdot 053$ & -0.041 & $0 \cdot 146$ & 1.023 & 0.966 & 1.079 & $1 \cdot 048$ & 0.485 \\
\hline Woodland & $\begin{array}{l}\text { Leaf life } \\
\text { span }\end{array}$ & Height & 86 & 0.038 & $0 \cdot 072$ & $0 \cdot 168$ & -0.015 & $0 \cdot 351$ & 1.069 & 0.958 & $1 \cdot 179$ & $1 \cdot 151$ & 0.487 \\
\hline Woodland & Leaf area & Height & 148 & $0 \cdot 351$ & 0 & $0 \cdot 988$ & 0.768 & $1 \cdot 208$ & $-0 \cdot 194$ & -0.373 & -0.015 & 0.422 & 0.623 \\
\hline
\end{tabular}

Table 3. Observed variance for each of the eight leaf functional traits, leaf size and the square root of leaf size, and plant height for all species together (1st row), woody species (3rd row), herbaceous species (5th row), angiosperms (7th row), gymnosperms (9th row), at global scale (11th row), biome scale (13th row) and habitat scale (15th row). Even rows contain the ratio of the variance in height to the variance in each trait. For example, in row 2, column 1, we see that the ratio of the variance in height to the variance in LMA across all species is 6.561, and thus, there is considerably more variance in height than in LMA. Note that the variance in height is greater than the variance in all functional traits examined save leaf size or the square root of leaf size, for some groupings. The last row represents the number of observations for each trait that fall within two standard deviations of the global mean. Note that rows 1:2 and 11:12 are identical, with 11:12 repeated simply to make it easier to compare to the global, biome and habitat level variances

\begin{tabular}{|c|c|c|c|c|c|c|c|c|c|c|c|}
\hline & $\begin{array}{l}\text { Log } \\
\text { LMA }\end{array}$ & $\begin{array}{l}\log \\
\text { LL }\end{array}$ & $\begin{array}{l}\log \\
N_{\text {mass }}\end{array}$ & $\begin{array}{l}\text { Log } \\
N_{\text {area }}\end{array}$ & $\begin{array}{l}\text { Log } \\
P_{\text {mass }}\end{array}$ & $\begin{array}{l}\log \\
P_{\text {area }}\end{array}$ & $\begin{array}{l}\text { Log } \\
A_{\text {mass }}\end{array}$ & $\begin{array}{l}\log \\
A_{\text {area }}\end{array}$ & $\begin{array}{l}\log _{10} \\
\text { leafsize }\end{array}$ & $\begin{array}{l}\log _{10} \text { sqrt } \\
\text { (leafsize) }\end{array}$ & $\begin{array}{l}\text { Log } \\
\text { height }\end{array}$ \\
\hline Variance all plants & $0 \cdot 073$ & $0 \cdot 168$ & $0 \cdot 045$ & $0 \cdot 048$ & 0.074 & $0 \cdot 071$ & $0 \cdot 112$ & $0 \cdot 042$ & 0.746 & 0.094 & 0.479 \\
\hline Height var/trait var & $6 \cdot 561$ & $2 \cdot 849$ & $10 \cdot 591$ & $10 \cdot 036$ & $6 \cdot 447$ & $6 \cdot 711$ & $4 \cdot 270$ & $11 \cdot 363$ & $0 \cdot 642$ & $5 \cdot 084$ & NA \\
\hline Variance woody & $0 \cdot 073$ & $0 \cdot 153$ & 0.044 & $0 \cdot 047$ & 0.075 & $0 \cdot 071$ & $0 \cdot 110$ & $0 \cdot 043$ & 0.736 & 0.096 & 0.363 \\
\hline Height var/trait var & 4.978 & $2 \cdot 369$ & $8 \cdot 312$ & $7 \cdot 783$ & 4.839 & $5 \cdot 126$ & $3 \cdot 300$ & $8 \cdot 526$ & 0.492 & $3 \cdot 778$ & NA \\
\hline Variance herbaceous & $0 \cdot 064$ & $0 \cdot 067$ & $0 \cdot 051$ & $0 \cdot 060$ & $0 \cdot 004$ & 0.037 & $0 \cdot 066$ & 0.039 & $0 \cdot 383$ & $0 \cdot 041$ & $0 \cdot 207$ \\
\hline Height var/trait var & $3 \cdot 245$ & $3 \cdot 071$ & $4 \cdot 081$ & $3 \cdot 429$ & $51 \cdot 753$ & $5 \cdot 565$ & $3 \cdot 132$ & $5 \cdot 313$ & 0.539 & $5 \cdot 057$ & NA \\
\hline Variance angiosperm & $0 \cdot 051$ & $0 \cdot 134$ & $0 \cdot 032$ & 0.036 & 0.072 & $0 \cdot 056$ & 0.068 & 0.032 & $0 \cdot 481$ & 0.705 & 0.47 \\
\hline Height var/trait var & $9 \cdot 224$ & $3 \cdot 514$ & $14 \cdot 53$ & $13 \cdot 16$ & $6 \cdot 548$ & 8.458 & $6 \cdot 916$ & 14.69 & 0.978 & 0.667 & NA \\
\hline Variance gymnosperm & 0.02 & $0 \cdot 043$ & 0.005 & $0 \cdot 012$ & $0 \cdot 018$ & 0.003 & $0 \cdot 022$ & $0 \cdot 008$ & $0 \cdot 124$ & $0 \cdot 037$ & 0.057 \\
\hline Height var/trait var & $2 \cdot 901$ & $1 \cdot 319$ & $11 \cdot 02$ & 4.693 & $3 \cdot 103$ & $16 \cdot 52$ & $2 \cdot 546$ & $6 \cdot 887$ & 0.456 & $1 \cdot 545$ & NA \\
\hline Variance global & $0 \cdot 073$ & $0 \cdot 168$ & $0 \cdot 045$ & $0 \cdot 048$ & $0 \cdot 074$ & $0 \cdot 071$ & $0 \cdot 112$ & $0 \cdot 042$ & 0.746 & $0 \cdot 094$ & $0 \cdot 479$ \\
\hline Height var/trait var & $6 \cdot 561$ & $2 \cdot 849$ & $10 \cdot 591$ & $10 \cdot 036$ & $6 \cdot 447$ & $6 \cdot 711$ & $4 \cdot 270$ & $11 \cdot 363$ & $0 \cdot 642$ & $5 \cdot 084$ & NA \\
\hline Mean biome var & $0 \cdot 038$ & $0 \cdot 136$ & 0.029 & 0.027 & 0.03 & 0.031 & $0 \cdot 08$ & 0.033 & $0 \cdot 375$ & $0 \cdot 261$ & $0 \cdot 24$ \\
\hline Height var/trait var & $6 \cdot 348$ & 1.763 & $8 \cdot 296$ & $8 \cdot 788$ & $8 \cdot 038$ & $7 \cdot 683$ & $3 \cdot 006$ & $7 \cdot 357$ & 0.639 & $0 \cdot 918$ & NA \\
\hline Mean habitat var & 0.037 & $0 \cdot 099$ & $0 \cdot 019$ & $0 \cdot 018$ & $0 \cdot 016$ & $0 \cdot 016$ & $0 \cdot 059$ & $0 \cdot 023$ & $0 \cdot 377$ & $0 \cdot 172$ & $0 \cdot 213$ \\
\hline Height var/trait var & $5 \cdot 806$ & $2 \cdot 163$ & $11 \cdot 19$ & $11 \cdot 9$ & $13 \cdot 51$ & $13 \cdot 56$ & $3 \cdot 599$ & $9 \cdot 306$ & $0 \cdot 565$ & $1 \cdot 238$ & NA \\
\hline$\%$ Within 2 SD mean & $95 \cdot 29$ & $97 \cdot 13$ & 94.57 & $95 \cdot 05$ & $93 \cdot 11$ & $95 \cdot 36$ & $93 \cdot 25$ & $96 \cdot 44$ & $96 \cdot 17$ & 98.09 & $95 \cdot 57$ \\
\hline
\end{tabular}

individual leaf area, regardless of the spatial scale (global, biome or habitat, Table 3). Seven out of nine of the traits had greater than $95 \%$ of their observations within two standard deviations of the mean, and the remaining two had greater than $93 \%$ (Table 3). Thus, based on Criteria 1-4, all LES traits exhibit little variation with plant height and may be considered effectively invariant within some modelling frameworks, perhaps most appropriately at global scales and within woody/herbaceous or angiosperm/ gymnosperm groupings.

While there is little dependence of LES traits on plant height within plant functional types or taxonomic groupings (angiosperm or gymnosperm), we do see systematic shifts in data that are of interest. For example, six of the nine traits showed no difference in slopes between angiosperm and gymnosperms, and five of those had a significant shift in elevation of the data (Fig. 2, Table 1). For a given height, gymnosperms had higher LMA and $P_{\text {area }}$, but lower $P_{\text {mass }}, N_{\text {mass }}, A_{\text {mass }}$ and $A_{\text {area }}$. The high
LMA in gymnosperms is consistent with their long life spans, and an increase in structural and/or defence tissue likely explains the lower mass-based nutrient concentrations and photosynthetic rates.

Also consistent with previous evaluations (Fonseca et al. 2000; Wright et al. 2007), individual leaf size increased modestly with plant height, but the reasons for this trend are not fully understood. Figure 3 shows that this trend is not apparent in all habitats and is in fact reversed in wet habitats such as tropical rain forest, upland pine forest and meadow tundra. The global trend seems mainly due to a large number of small-statured angiosperm species with small leaves (Fig. 2c), many of these occurring in the drier habitats (Fig. 3c). Small leaves have thinner boundary layers, which facilitate convective heat loss and thus help prevent overheating (Givnish 1978), and which also increase stomatal control over transpiration rates (Jarvis \& McNaughton 1986). Heat loss and transpiration are, however, also influenced by several other factors such as 

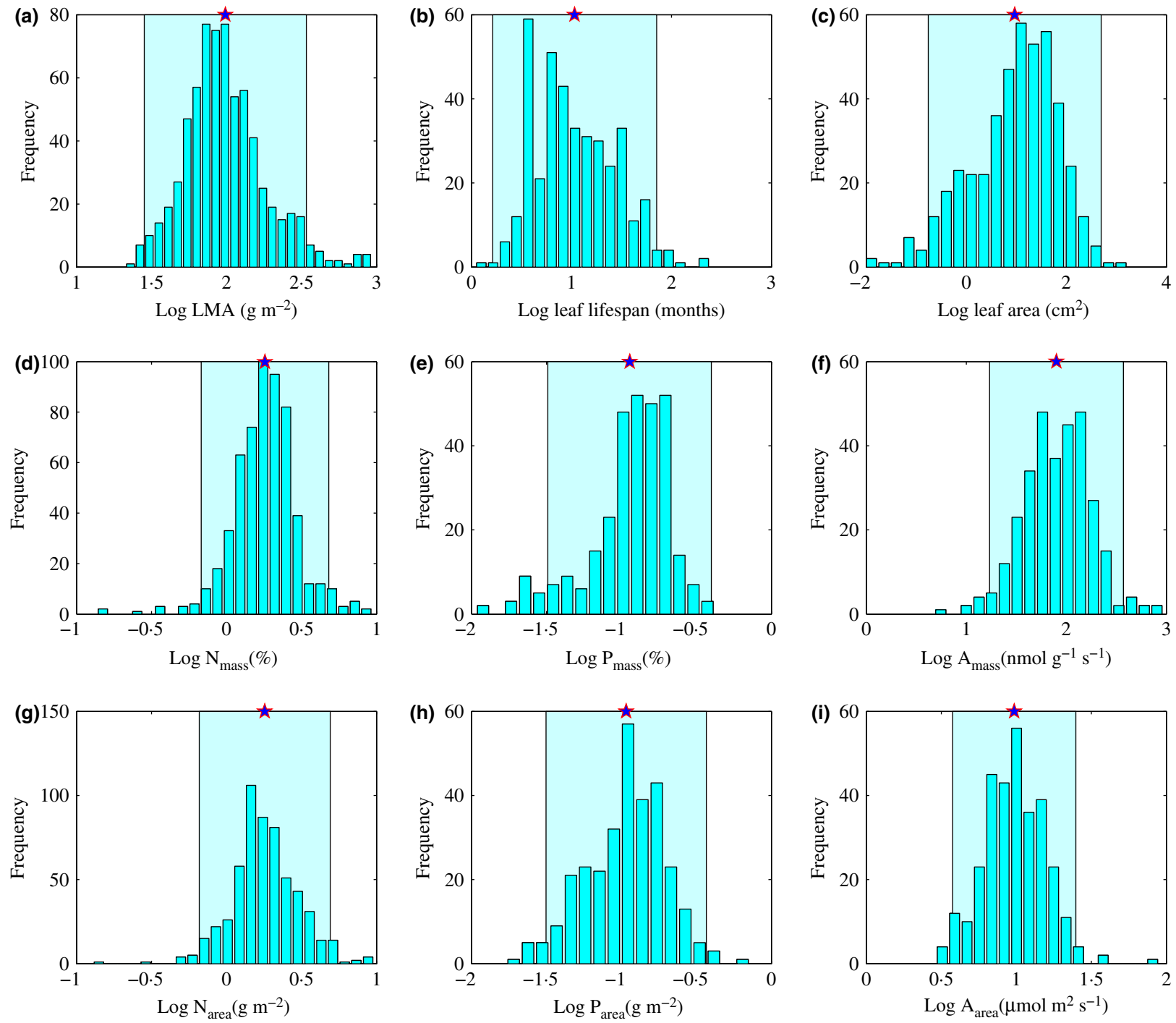

Fig. 1. Panels a-i are histograms of the $\log 10$-transformed data for each of the LES traits and leaf size. The red star represents the mean for each distribution, and each shaded, light green rectangle represents plus/minus two standard deviations from the mean. The percentage of values that fall within two standard deviations of the mean for each plot are reported in the last row of Table 3 . Note that all distributions are modal which satisfies our second proposed criteria for evaluating invariant traits.

microclimate, canopy structure and other leaf traits such as their angle, reflectivity, clumping and being lobed or compound, indicating that alternative strategies are possible in some environments and that the association of small leaf size with arid habitats is not absolute. Reducing leaf temperature and transpiration is much less important in cool and/or moist environments and even less so where such environments are also shaded, as in the understorey or mid-story of forests, where the premium is on enhanced light capture. Indeed, the global positive correlation between leaf size and plant height is reversed in such habitats, such as wet forests (Fig. 3c). An additional reason for this reversed trend may be the greater support and hydraulic costs of larger leaves (Givnish 1978; Niinemets, Portsmuth \& Tobias 2006; Milla \& Reich 2007; Niinemets et al. 2007; Niinemets, Portsmuth \& Tobias 2007; Niklas et al. 2007; Price \& Enquist 2007; Price \& Weitz 2010) and their greater vulnerability to hydraulic disruption due to lower density of secondary veins (Scoffoni et al. 2011). As with all LES traits, leaf size is influenced by opposing effects of environmental factors and by integration among other plant traits (Milla \& Reich 2011). In contrast to all invariant LES traits, the range of variation in leaf size is very large, and environmental influences are strong enough to cause some global and within-habitat correlations with plant height. Understanding these drivers of leaf size variability is clearly an area in need of further inquiry and synthesis.

The MTE model has been supported by some empirical studies identifying allometric phenomena in plants that exhibit near $1 / 4$ scaling relationships (West, Brown \& Enquist 1999; Enquist 2002; Enquist, West \& Brown 2009; West, Enquist \& Brown 2009). However, under what conditions $1 / 4$ power scaling is observed remains an area of 

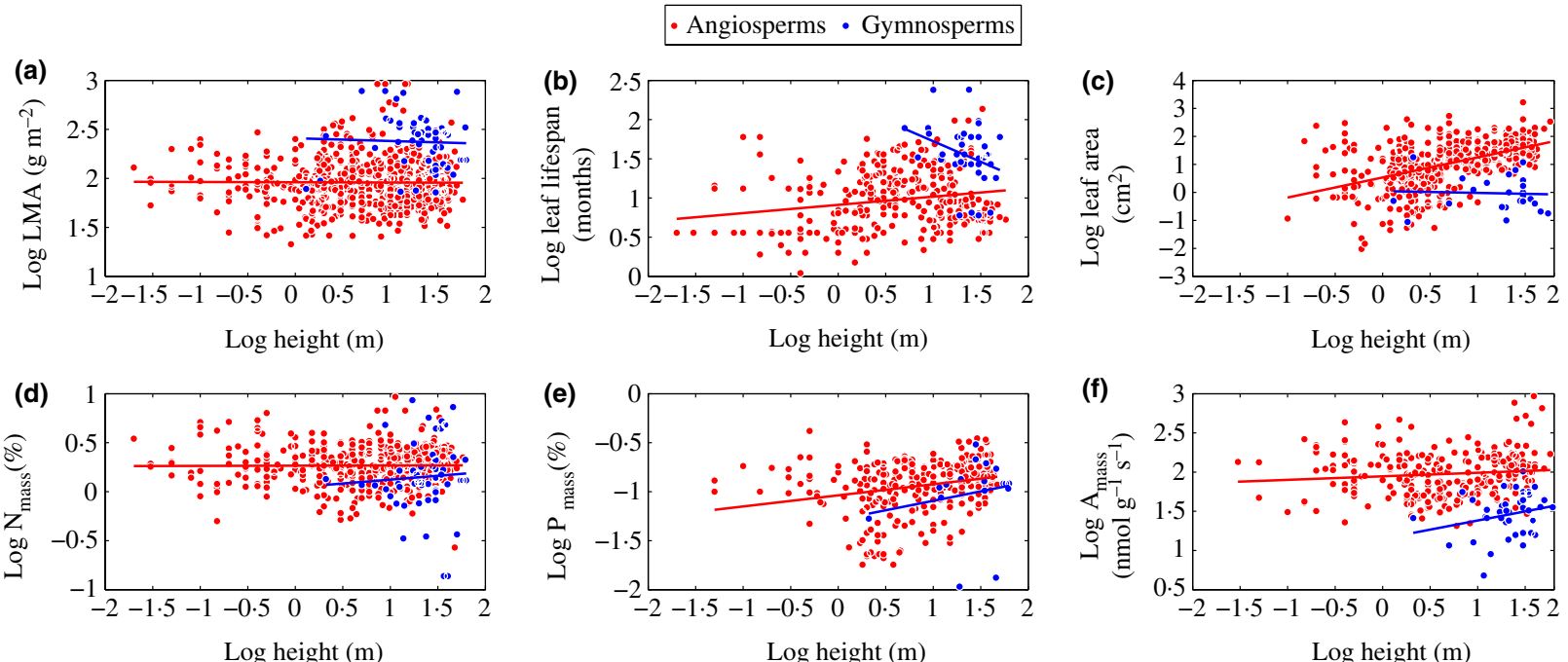

Log height $(\mathrm{m})$
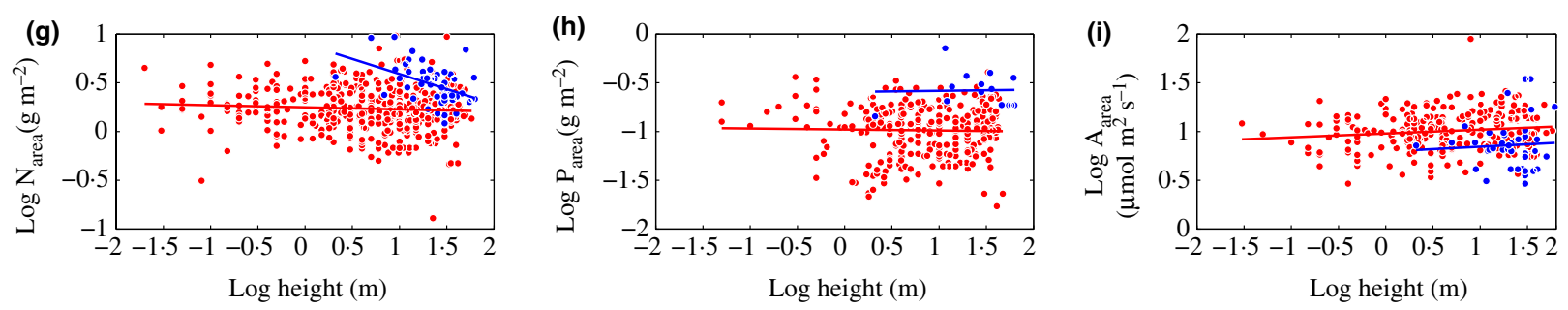

Fig. 2. LMA, leaf life span, leaf area, $N_{\text {mass }}, P_{\text {mass }}, A_{\text {mass }}, N_{\text {area, }} P_{\text {area }}$ and $A_{\text {area }}$ as a function of height (panels a-i) across angiosperms (red circles) and gymnosperms (blue circles). All data are logarithmically transformed (base 10) prior to plotting. Regression statistics for all relationships are reported in Table 1.

active interest and debate. For example, with respect to the hypothesized $3 / 4$ scaling of metabolism with mass, data both supporting (Meinzer et al. 2005; Mori et al. 2010) and refuting (Reich et al. 2006; Sperry et al. 2012) this idea have been presented. Numerous additional supporting examples and exceptions have also been described (see reviews in Enquist 2002; Price et al. 2010, 2012; Sibly, Brown \& Kodric-Brown 2012). However, to date, most tests of MTE have focused on evaluating model predictions rather than assessing the validity of the model's simplifying assumptions (Price et al. 2012; but see Sperry et al. 2012), and thus, it is difficult to know whether MTE's mechanistic underpinnings are supported. Our analysis indicates that the assumption that LES traits vary little with respect to interspecific plant height is generally quite robust. Thus, within some broad-scale modelling approaches (such as MTE), it is reasonable to assume that the average traits of a leaf do not vary with plant height across species. For other modelling purposes, for example within closed canopy forests, it may be important to incorporate a realistic range of functional trait variation among species and not treat trait values as constants. Future sensitivity analysis, as we describe above, might explore how the observed variation in LES traits influences MTE predictions. We note that considerable growing evidence for leaf trait variation with size within species (Cornelissen 1999; Thomas \& Winner 2002; Kenzo et al. 2006; Machado \& Reich 2006; Cavaleri et al. 2010; Thomas
2010; Sendall \& Reich 2013) suggests that such assumptions should be used only within carefully chosen contexts.

While some LES traits may be considered effectively invariant, as we show, leaf area increases with plant height, in violation of the simplifying assumption of MTE (West, Enquist \& Brown 2009). As seen in Fig. 2c and Table 1, this increase is modest, but systematic, increasing roughly 100 -fold over a 3000-fold increase in plant height. Given the strong allometric dependence of leaf area on petiole diameter (Price \& Enquist 2007; Price et al. 2009), this means that petiole size and either the number and/or dimensions of conduits within leaves also increase with plant height. Recent efforts to bring general models for plant hydraulic design closer to known empirical patterns have proven fruitful (Savage et al. 2010). For example, detailed, species-specific parameterizations that incorporate variability in hydraulic and biomechanical traits provide better estimates of whole tree sap flow rates (Sperry et al. 2012; von Allmen et al. 2012) than earlier, more general approaches (West, Brown \& Enquist 1999). We suggest that the systematic interspecific increase in leaf size may be an important target for future integration and synthesis.

In conclusion, we have shown that at macroscopic scales, interspecific differences in LES traits typically have low variance and are uncorrelated or weakly correlated with plant height. The relative variance in LES traits vs. height varies across traits and may be considered 'invariant' within some modelling approaches. Future work is 


\begin{tabular}{|cccccccc|}
\hline$\Delta$ Chaparral & $\Delta$ Desert Grassland & $\Delta$ High elevation Grasslands & $\Delta$ Meadow Tundra & $\bullet$ Oak Forests & Open Temperate Forest & $\bullet$ Semi-arid 'Mallee' Shrubland $\bullet$ Semi-arid Woodland \\
\hline Temperate Forest & Tropical Dry Forest & $\star$ Tropical Montane Cloud Forest & $*$ Tropical Rainforest & $\|$ Tundra & " Upland Pine Forests & "Warm Temperate Forest & " Warm Temperate Rainforest \\
\hline
\end{tabular}
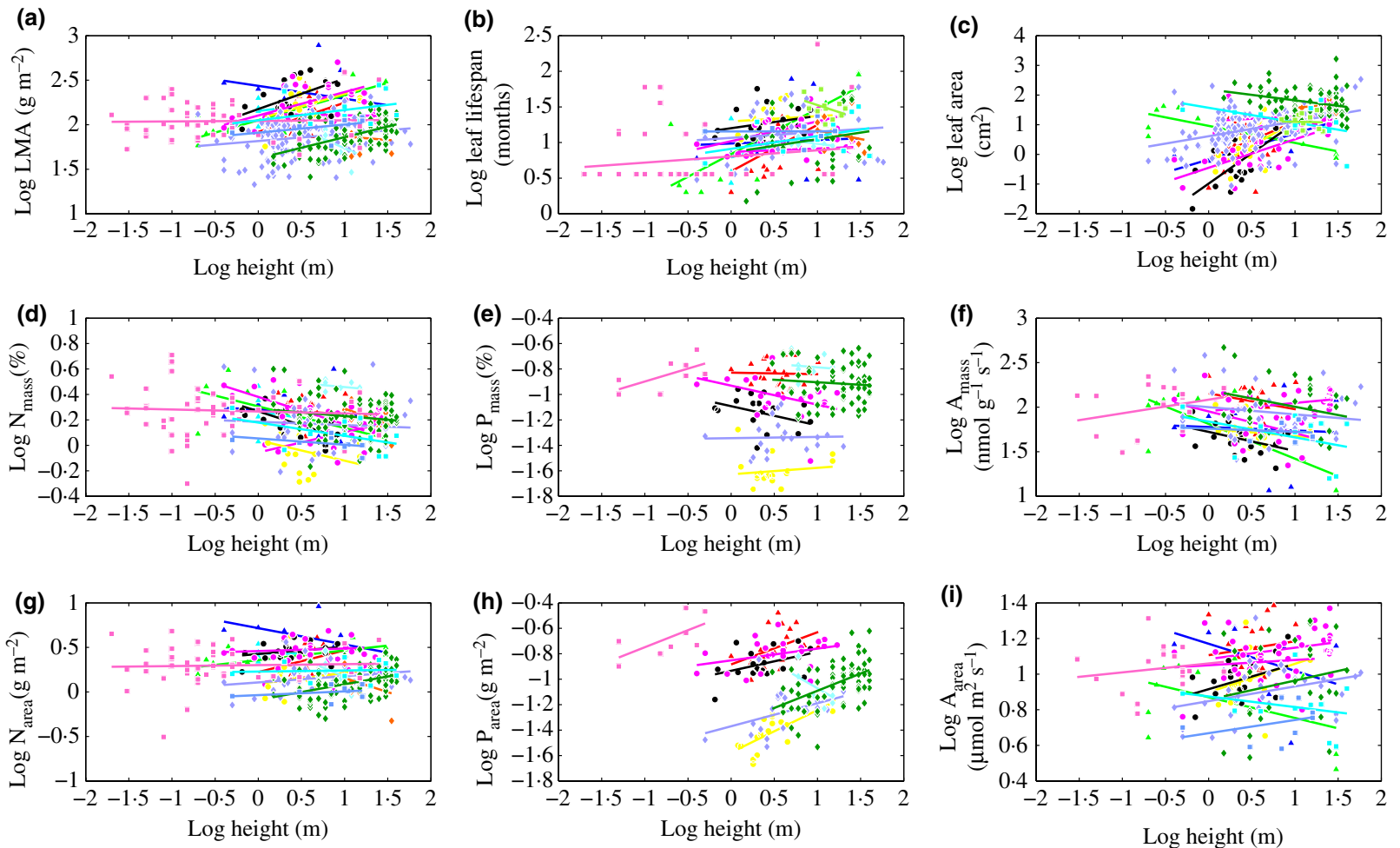

Fig. 3. LMA, leaf life span, leaf area, $N_{\text {mass }}, P_{\text {mass }}, A_{\text {mass }}, N_{\text {area, }} P_{\text {area }}$ and $A_{\text {area }}$ as a function of height (panels a-i) within the following habitat types: chaparral (red triangles), desert grasslands (dark blue triangles), high elevation grasslands (light blue triangles), meadow tundra (green triangles), oak forests (pink circles), open temperate forests (yellow circles), semi-arid 'Mallee' shrubland (black circles), semiarid woodlands (pink circles), temperate forests (blue diamonds), tropical dry forests (light blue diamonds), tropical montane cloud forests (orange diamonds), tropical rain forests (dark green diamonds), tundra (pink squares), upland pine forests (turquoise squares), warm temperate forests (blue squares) and warm temperate rain forests (light green squares). All data are logarithmically transformed (base 10) prior to plotting. Coloured lines represent ordinary least-squares regression fits to data, with line colours corresponding to symbol colours. Regression statistics for all relationships are reported in Table S2.

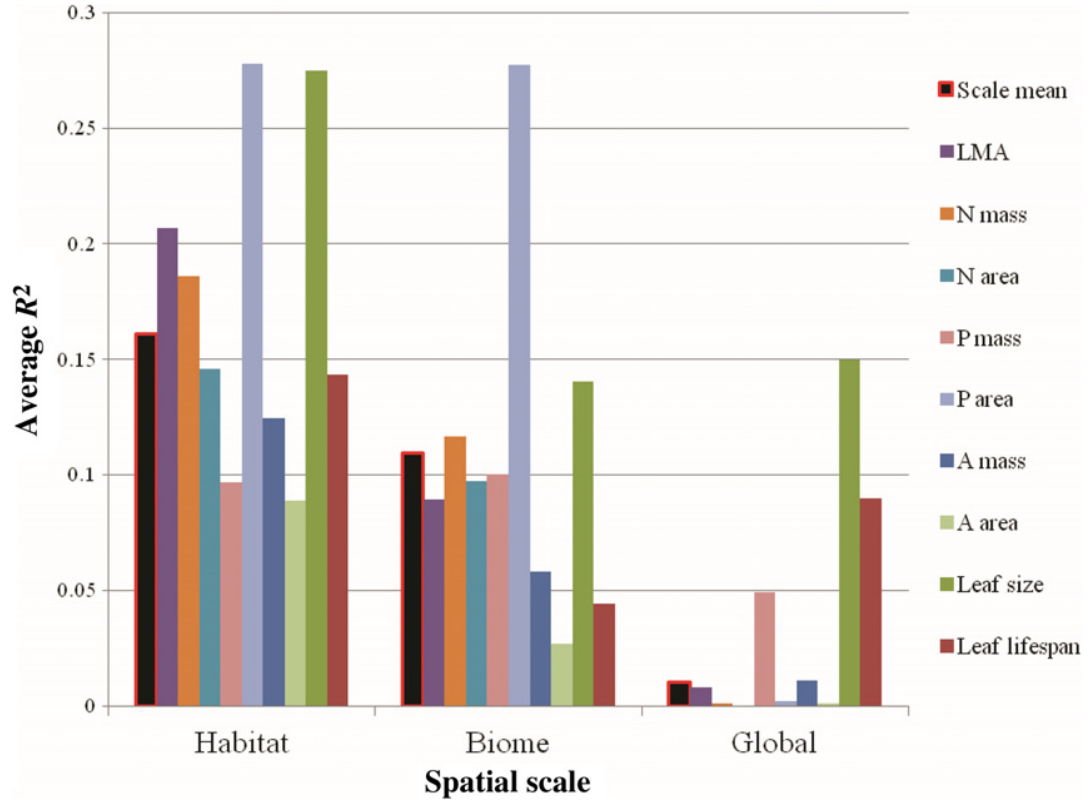

Fig 4. The average observed $R^{2}$ value for each trait at habitat, biome and global scales. $R^{2}$ values are higher on average at smaller spatial scales which suggests that there may be important size based trends in some LES traits at local scales, but that this signal weakens at larger scales. 
needed, however, to fully understand the modest, but systematic increase in leaf area with plant height. We have also highlighted that invariance is an elusive concept statistically, yet we highlight several criteria by which investigators might identify traits that approach invariance.

\section{Acknowledgements}

CAP is supported by an ARC Discovery Early Career Research Award and IJW by an ARC Future Fellowship. We declare no conflict of interest.

\section{Data accessibility}

Data for this article have been archived in Dryad: doi: 10.5061/dryad.r3n45

\section{References}

Ackerly, D. (2004) Functional strategies of chaparral shrubs in relation to seasonal water deficit and disturbance. Ecological Monographs, 74, 25 54.

von Allmen, E.I., Sperry, J.S., Smith, D.D., Savage, V., Enquist, B.J., Reich, P.B. et al. (2012) A species-level model for metabolic scaling of trees II. Testing in a ring- and diffuse-porous species. Functional Ecology, 26, 1066-1076.

Baraloto, C., Paine, C.E.T., Poorter, L., Beauchene, J., Bonal, D., Domenach, A.M. et al. (2010) Decoupled leaf and stem economics in rain forest trees. Ecology Letters, 13, 1338-1347.

Bookstein, F.L. (1991) Morphometric Tools for Landmark Data Geometry and Biology. Cambridge University Press, Cambridge.

Briand, F. \& Cohen, J.E. (1984) Community food webs have scale-invariant structure. Nature, 307, 264-267.

Brody, S. (1945) Bioenergetics and Growth. Reinhold Publishing Corporation, New York.

Brown, J.H., Gillooly, J.F., Allen, A.P., Savage, V.M. \& West, G.B. (2004) Toward a metabolic theory of ecology. Ecology, 85, 1771-1789.

Calder, W.A. (1984) Size, Function, and Life History. Harvard University Press, Cambridge, MA.

Cavaleri, M.A., Oberbauer, S.F., Clark, D.B., Clark, D.A. \& Ryan, M.G. (2010) Height is more important than light in determining leaf morphology in a tropical forest. Ecology, 91, 1730-1739.

Charnov, E.L. (1993) Life History Invariants: Some Explorations of Symmetry in Evolutionary Ecology. Oxford University Press, Oxford.

Coomes, D.A. (2006) Challenges to the generality of the WBE theory. Trends in Ecology \& Evolution, 11, 593-596.

Cornelissen, J.H.C. (1999) A triangular relationship between leaf size and seed size among woody species: allometry; ontogeny; ecology and taxonomy. Oecologia, 118, 248-255.

Diaz, S., Hodgson, J.G., Thompson, K., Cabido, M., Cornelissen, J.H.C., Jalili, A. et al. (2004) The plant traits that drive ecosystems: evidence from three continents. Journal of Vegetation Science, 15, 295-304.

Dodds, P.S., Rothman, D.H. \& Weitz, J.S. (2001) Re-examination of the "3/4-law" of metabolism. Journal of Theoretical Biology, 209, 927.

Enquist, B.J. (2002) Universal scaling in tree and vascular plant allometry: toward a general quantitative theory linking plant form and function from cells to ecosystems. Tree Physiology, 22, 1045-1064.

Enquist, B.J. \& Niklas, K.J. (2002) Global allocation rules for patterns of biomass partitioning in seed plants. Science, 295, 1517-1520.

Enquist, B.J., West, G.B. \& Brown, J.H. (2009) Extensions and evaluations of a general quantitative theory of forest structure and dynamics. Proceedings of the National Academy of Sciences of the United States of America, 106, 7046-7051.

Enquist, B., Allen, A., Brown, J., Gillooly, J., Kerkhoff, A., Niklas, K. et al. (2007) Does the exception prove the rule? Nature, 445, E9-E10.

Falster, D.S. \& Westoby, M. (2005) Alternative height strategies among 45 dicot rain forest species from tropical Queensland, Australia. Journal of Ecology, 93, 521-535.

Fonseca, C.R., Overton, J.M., Collins, B. \& Westoby, M. (2000) Shifts in trait-combinations along rainfall and phosphorus gradients. Journal of Ecology, 88, 964-977.
Galilei, G. (1638) Discorsi e Dimostrazioni Matematiche, Intorno a Due Nuove Scienze. Appresso gli Elsevirii, Leida.

Givnish, T.J. (1978) Ecological aspects of plant morphology: leaf form in relation to environment. Theoretical Plant Morphology (ed. R. Sattler), pp. 83-142. Leiden University Press, Leiden, The Netherlands.

Glazier, D.S. (2006) The 3/4-power law is not universal: evolution of isometric, ontogenetic metabolic scaling in pelagic animals. BioScience, 56, 325-332.

Hallik, L., Niinemets, Ü. \& Wright, I.J. (2009) Are species shade and drought tolerance reflected in leaf-level structural and functional differentiation in Northern Hemisphere temperate woody flora? The New Phytologist, 184, 257-274.

Holm, S. (1979) A simple sequentially rejective multiple test procedure. Scandinavian Journal of Statistics, 6, 65-70.

Jarvis, P.G. \& McNaughton, K.G. (1986) Stomatal control of transpiration - scaling up from leaf to region. Advances in Ecological Research, 15, 149.

Kenzo, T., Ichie, T., Watanabe, Y., Yoneda, R., Ninomiya, I. \& Koike, T. (2006) Changes in photosynthesis and leaf characteristics with tree height in five dipterocarp species in a tropical rain forest. Tree Physiology, 26, 865-873.

Kerkhoff, A.J. \& Enquist, B.J. (2009) Multiplicative by nature: why logarithmic transformation is necessary in allometry. Journal of Theoretical Biology, 257, 519-521.

Kleiber, M. (1932) Body size and metabolism. Hilgardia, 6, 315-353.

Kooijman, S.A.L.M. (1993) Dynamic Energy Budgets in Biological Systems. Cambridge University Press, Cambridge.

Kozlowski, J. \& Konarzewski, M. (2004) Is West, Brown and Enquist's model of allometric scaling mathematically correct and biologically relevant? Functional Ecology, 18, 283-289.

Laliberté, E., Shipley, B., Norton, D.A. \& Scott, D. (2012) Which plant traits determine abundance under long-term shifts in soil resource availability and grazing intensity? Journal of Ecology, 100, 662-677.

Machado, J.L. \& Reich, P.B. (2006) Dark respiration rate increases with plant size in saplings of three temperate tree species despite decreasing tissue nitrogen and nonstructural carbohydrates. Tree Physiology, 26, 915-923.

Meinzer, F.C., Bond, B.J., Warren, J.M. \& Woodruff, D.R. (2005) Does water transport scale universally with tree size? Functional Ecology, 19, 558-565.

Milla, R. \& Reich, P.B. (2007) The scaling of leaf area and mass: the cost of light interception increases with leaf size. Proceedings of the Royal Society B, 274, 2109-2114.

Milla, R. \& Reich, P.B. (2011) Multi-trait interactions, not phylogeny, finetune leaf size reduction with increasing altitude. Annals of Botany, 107, 455-465.

Mori, S., Yamaji, K., Ishida, A., Prokushkin, S.G., Masyagina, O.V., Hagihara, A. et al. (2010) Mixed-power scaling of whole-plant respiration from seedlings to giant trees. Proceedings of the National Academy of Sciences of the United States of America, 107, 1447-1451.

Muller-Landau, H.C., Condit, R.S., Chave, J., Thomas, S.C., Bohlman, S.A., Bunyavejchewin, S. et al. (2006a) Testing metabolic ecology theory for allometric scaling of tree size, growth and mortality in tropical forests. Ecology Letters, 9, 575-588.

Muller-Landau, H.C., Condit, R.S., Harms, K.E., Marks, C.O., Thomas, S.C., Bunyavejchewin, S. et al. (2006b) Comparing tropical forest tree size distributions with the predictions of metabolic ecology and equilibrium models. Ecology Letters, 9, 589-602.

Nee, S., Colegrave, N., West, S.A. \& Grafen, A. (2005) The illusion of invariant quantities in life histories. Science, 309, 1236-1239.

Nee, S., Colegrave, N., West, S.A. \& Grafen, A. (2006) Response to comment on 'The illusion of invariant quantities in life histories'. Science, 312, 198.

Niinemets, U. (2010) A review of light interception in plant stands from leaf to canopy in different plant functional types and in species with varying shade tolerance. Ecological Research, 25, 693-714.

Niinemets, U., Portsmuth, A. \& Tobias, M. (2006) Leaf size modifies support biomass distribution among stems, petioles and mid-ribs in temperate plants. New Phytologist, 171, 91-104.

Niinemets, U., Portsmuth, A. \& Tobias, M. (2007) Leaf shape and venation pattern alter the support investments within leaf lamina in temperate species: a neglected source of leaf physiological differentiation? Functional Ecology, 21, 28-40.

Niinemets, U., Portsmuth, A., Tena, D., Tobias, M., Matesanz, S. \& Valladares, F. (2007) Do we underestimate the importance of leaf size in 
plant economics? Disproportional scaling of support costs within the spectrum of leaf physiognomy. Annals of Botany, 100, 283-303.

Niklas, K.J. (1994) Plant Allometry: The Scaling of Form and Process. University Chicago Press, Chicago.

Niklas, K.J., Cobb, E.D., Niinemets, Ü., Reich, P.B., Sellin, A., Shipley, B. et al. (2007) 'Diminishing returns' in the scaling of functional leaf traits across and within species. Proceedings of the National Academy of Science of the United States of America, 104, 8891-8896.

Peters, R.H. (1983) The Ecological Implications of Body Size. Cambridge University Press, Cambridge.

Preston, F.W. (1960) Time, space and the variation of species. Ecology, 41, 785-790.

Price, C.A. \& Enquist, B.J. (2007) Scaling mass and morphology in leaves: an extension of the WBE model. Ecology, 88, 1132-1141.

Price, C.A., Enquist, B.J. \& Savage, V.M. (2007) A general model for allometric covariation in botanical form and function. Proceedings of the National Academy of Sciences of the United States of America, 104, 13204-13209.

Price, C.A. \& Weitz, J.S. (2010) Zero-sum allocational strategies determine the allometry of specific leaf area. American Journal of Botany, 97, 7 .

Price, C.A., Ogle, K., White, E.P. \& Weitz, J.S. (2009) Evaluating scaling models in biology using hierarchical Bayesian approaches. Ecology Letters, 12, 641-651.

Price, C.A., Gillooly, J.F., Allen, A.P., Weitz, J.S. \& Niklas, K.J. (2010) The metabolic theory of ecology: prospects and challenges for plant biology. New Phytologist, 188, 696-710.

Price, C.A., Weitz, J.S., Savage, V.M., Stegen, J.C., Clarke, A., Coomes, D.A. et al. (2012) Testing the metabolic theory of ecology. Ecology Letters, 15, 1465-1474.

Price, C.A., Wright, I.J., Ackerly, D.D., Niinemets, Ü., Reich, P.B. \& Veneklaas, E.J. (2014) Data from: are leaf functional traits 'invariant' with plant size, and what is 'invariance' anyway? Dryad Digital Repository. doi: $10.5061 /$ dryad.r3n 45

Reich, P.B. (2014) The world-wide 'fast-slow' plant economics spectrum: a traits manifesto. Journal of Ecology, 102, 275-301.

Reich, P.B., Walters, M.B. \& Ellsworth, D.S. (1997) From tropics to tundra: global convergence in plant functioning. Proceedings of the National Academy of Sciences of the United States of America, 94, 13730-13734.

Reich, P.B., Ellsworth, D.S., Walters, M.B., Vose, J.M., Gresham, C., Volin, J.C. et al. (1999) Generality of leaf trait relationships: a test across six biomes. Ecology, 80, 1955-1969.

Reich, P.B., Tjoelker, M.G., Machado, J.L. \& Oleksyn, J. (2006) Universal scaling of respiratory metabolism, size and nitrogen in plants. Nature, 439, 457-461.

Rubner, M. (1883) Über den Einfluß der Körpergröße auf Stoff- und Kraftwechsel. Zeitschrift fur Biologie, 19, 535-562.

Savage, V.M., Deeds, E.J. \& Fontana, W. (2008) Sizing up allometric scaling theory. Plos Computational Biology, 4, 17 .

Savage, V.M., White, E.P., Moses, M.E., Ernest, S.K.M., Enquist, B.J. \& Charnov, E.L. (2006) Comment on 'The illusion of invariant quantities in life histories'. Science, 312, 198B.

Savage, V.M., Bentley, L.P., Enquist, B.J., Sperry, J.S., Smith, D.D., Reich, P.B. et al. (2010) Hydraulic trade-offs and space filling enable better predictions of vascular structure and function in plants. Proceedings of the National Academy of Sciences of the United States of America, 107, 22722-22727.

Schmidt-Nielsen, K. (1984) Scaling: Why is Animal Size so Important? Cambridge University Press, Cambridge.

Scoffoni, C., Rawls, M., McKown, A., Cochard, H. \& Sack, L. (2011) Decline of leaf hydraulic conductance with dehydration: relationship to leaf size and venation architecture. Plant Physiology, 156, 832-843.

Sendall, K.M. \& Reich, P.B. (2013) Variation in leaf and twig CO2 flux as a function of plant size: a comparison of seedlings, saplings and trees. Tree Physiology, 33, 713-729.

Sibly, R.M., Brown, J.H. \& Kodric-Brown, A. (2012) Metabolic Ecology: A Scaling Approach. Wiley-Blackwell, West Sussex.
Sperry, J.S., Smith, D.D., Savage, V., Enquist, B.J., McCulloh, K.A., Reich, P.B. et al. (2012) A species-level model for metabolic scaling in trees I. Exploring boundaries to scaling space within and across species. Functional Ecology, 26, 1054-1065.

Thomas, S.C. (1996) Asymptotic height as a predictor of growth and allometric characterizations in Malaysian Rain Forest trees. American Journal of Botany, 83, 556-566.

Thomas, S.C. (2010) Photosynthetic capacity peaks at intermediate size in temperate deciduous trees. Tree Physiology, 30, 555-573.

Thomas, S.C. \& Winner, W.E. (2002) Photosynthetic differences between saplings and adult trees: an integration of field results by meta-analysis. Tree Physiology, 22, 117-127.

Thompson, D.W. (1917) On Growth and Form. Cambridge University Press, Cambridge.

Violle, C., Navas, M.L., Vile, D., Kazakou, E., Fortunel, C., Hummel, I. et al. (2007) Let the concept of trait be functional! Oikos, 116, 882-892.

Warton, D.I., Wright, I.J., Falster, D.S. \& Westoby, M. (2006) Bivariate line-fitting methods for allometry. Biological Reviews, 81, 259-291.

West, G.B., Brown, J.H. \& Enquist, B.J. (1997) A general model for the origin of allometric scaling laws in biology. Science, 276, 122-126.

West, G.B., Brown, J.H. \& Enquist, B.J. (1999) A general model for the structure and allometry of plant vascular systems. Nature, 400, 664-667.

West, G.B., Brown, J.H. \& Enquist, B.J. (2001) A general model for ontogenetic growth. Nature, 413, 628-631.

West, G.B., Enquist, B.J. \& Brown, J.H. (2009) A general quantitative theory of forest structure and dynamics. Proceedings of the National Academy of Sciences of the United States of America, 106, 7040-7045.

Whittaker, R.H. (1975) Communities and Ecosystems. Macmillan, New York.

Wright, I.J., Reich, P.B., Westoby, M., Ackerly, D.D., Baruch, Z., Bongers, F. et al. (2004) The worldwide leaf economics spectrum. Nature, 428, $821-827$.

Wright, I.J., Ackerly, D.D., Bongers, F., Harms, K.E., Ibarra-Manriquez, G., Martinez-Ramos, M. et al. (2007) Relationships among ecologically important dimensions of plant trait variation in seven Neotropical forests. Annals of Botany, 99, 1003-1015.

Received 22 May 2013; accepted 13 April 2014

Handling Editor: Jennifer Baltzer

\section{Supporting Information}

Additional Supporting information may be found in the online version of this article:

Fig. S1. LMA, leaf lifespan, leaf area, $N_{\text {mass }}, P_{\text {mass }}, A_{\text {mass }}, N_{\text {area, }}$ $P_{\text {area, }}$ and $A_{\text {area }}$ as a function of height across herbaceous (green triangles) and woody species (blue circles and stars).

Fig. S2. LMA (Panel A), leaf lifespan (Panel B), and leaf area (Panel C) as a function of height within the following biome types; Boreal (dark blue triangles), Alpine (light blue circles), Woodlands (green triangles), Temperate Forests (pink squares), Tropical Forests (red triangles), and Rainforests (yellow stars).

Table S1. Plant height and leaf functional trait data used in the study: For each species the binomial, database (GLOPNET or BigTree), biome, habitat, growth form, taxonomic group (angiosperm or gymnosperm) and functional trait data (as described in the methods) are listed.

Table S2. Ordinary least squares regression results for the 109 bivariate relationships we examined when grouping species by habitat. 